Studia Anglica Posnaniensia 48/1, 2013

doi: 10.2478/stap-2013-0002

\title{
SEMANTIC CHANGE IN AFRICAN AMERICAN SLANG
}

\author{
MACIEJ WIDAWSKI
}

University of Social Sciences, Warsaw

\begin{abstract}
Semantic change is an important part of African American slang and involves two mechanisms: figuration and shifting. Both are enormously productive and account for numerous slang expressions based on standard English. This paper presents these processes in detail. Partially drawing from the author's earlier publications, the presentation is based on lexical material from a sizable database of citations from contemporary African American sources collected through extensive fieldwork in the United States in recent years.
\end{abstract}

Keywords: semantic change, figuration, semantic shifting, American slang

\section{Introduction}

Semantic change is a well-established vehicle for language development. It quintessentialy involves two main processes: figuration, which makes use of metaphor, metonymy and related figurative means; and semantic shifting, which includes generalization, specialization, melioration and pejoration. Although figuration is traditionally associated with poetry while shifting is commonly linked with historical change, both are productive in everyday speech and are as much a part of language as any other linguistic mechanism. Figuration and shifting are also important mechanisms of semantic change in African American slang. Their popularity and productivity disproves the popular claims of African American speech's alleged semantic poverty and expressive deficiency with regard to standard English (see Smitherman 1977).

This paper presents these semantic processes in detail, and thus falls within the spectrum of descriptive studies of African American lexicon (for instance, 
see Baugh 1983, Dillard 1977, Folb 1980, Major 1994, Rickford 1999, Smitherman 2000). Partially drawing from my book African American: A Linguistic Description (forthcoming) and an earlier monograph on African American lexicon (Widawski \& Kowalczyk 2012), the presentation is based on lexical material from a large database of citations which also served as the basis for these books. The idea was to get as much exposure to African American slang as possible and to record its usage in natural contexts from various contemporary sources. To that end, the citations have been collected from diverse contemporary African American sources including film, television, magazines, literature, Internet, and utterances by African Americans; however, non-African American sources were also included in the database to see the impact African American slang has had on the general slang used in America. The material was collected through extensive fieldwork in the United States in recent years, and research at academic institutions such as Columbia University, Yale University, the University of California at Berkeley, and the Library of Congress. The methods used in data collection and applied in the creation of the database were varied, but largely traditional: data was recorded in the form of written notes or dictaphone recordings, which were systematically entered into the database. The Internet was used extensively, and a sizable portion of citations was copied directly from online sources. The reading, listening and watching procedures were extensive and represent several hundred hours of analyzing text, sound and images, which translated into almost 15,000 citations.

Let us first briefly explain the terminology connected with the type of language discussed here. The term slang, as used in the title of this paper, is especially troublesome and has generated many often discordant definitions and characterizations. This is due in part to its fleeting character, alleged vagueness, and very change of meaning over time. As a result, definitions of slang abound and, to quote Chapman (1986: x): 'like proverbial blind men describing an elephant, all correctly, none sufficiently, we tend to stress one aspect or another of slang.' Accordingly, some scholars such as Thorne (1990: iii) focus on the stylistic dimension of slang, especially its marked informality or colloquial character. Other scholars such as Chapman (in Kipfer 2007: xi) tend to emphasize its psychological element, principally the application of slang to convey emotions. Others such as Eble (1996: 11) emphasize the social element of slang with its function as a marker of group identification. Finally, scholars such as Dumas and Lighter (1978: 5-17) stress the rhetorical aspects of slang with its deliberate use for desired stylistic effects.

In an attempt to formulate a more holistic definition, one can integrate all of the above aspects and define slang as 'the most informal and unconventional type of vocabulary. It is perceived as expressive, catchy, and undignified. It consists of standard expressions modified in some way or appended with new, 
often figurative, meanings, and sometimes of entirely novel expressions. Slang is coined chiefly by members of social, occupational or ethnic groups which are typically separate from mainstream society, yet it is often adopted by larger social segments. It is employed in place of standard expressions to convey some extra information of a psychological, social or rhetorical nature. It thus provides alternative, highly informal synonyms for referents already named in the language, but sometimes gives names for referents for which there are no standard expressions, or which have yet to be named' (adapted from Widawski \& Kowalczyk 2012: 18).

The above definition is especially important in the context of African American slang. Aside from defining the type, formation and functions of slang, it also specifies its coiners and users: 'members of social, occupational or ethnic groups which are typically separate from mainstream society'. It also mentions the dissemination of slang among larger segments of society. Such is the nature of nearly any type of slang, but it is especially applicable to African American slang.

The second term used in the title is African American. Alternatively termed African American Vernacular, it is a fairly broad and general term for the speech of Black Americans. Significantly, as Baugh (in Mesthrie 2001: 709) points out, the name suggests a direct relationship to the linguistic legacy of slavery in the United States: in that, the term refers exclusively to the speech of the descendants of African slaves rather than the speech of recent African immigrants to the United States. The addition of 'vernacular' suggests that it is used by ordinary working-class speakers rather by all African Americans. The term is a part of numerous compound phrases such as the one featured in title of this paper. In this sense, 'African American slang' means slang coined and used by African Americans in the United States.

Naturally, both terms could be discussed in a larger terminological context. For instance, slang could be contrasted with colloquialism, non-standard language, vulgarism, taboo, euphemism, jargon, idiom, neologism or dialect, while African American could be compared to African American Vernacular English, Afro-American Vernacular English, Black English Vernacular, Ebonics or Gangsta Talk. However, the confines of this paper prevent any such lengthy discussions. For a more detailed comparison of these terms, see Widawski (forthcoming).

\section{Figuration}

Figuration is a well-known process of semantic change. It involves a word gaining further, non-literal meanings, specifically through metaphor and metonymy. English lexicon abounds in meanings created in this way: nature 
spoke, living death and crown of England are all instances of these. Although such figures of speech have long been salient features of poetry, they are also used frequently in everyday speech. In fact, as claimed and illustrated by Lakoff and Johnson (1980: ix), figuration is central to thought, cognition and ordinary, non-literary language.

Figuration is an important semantic process in African American slang, and possibly the third most productive source of enriching slang lexicon after compounding and affixation. As has been already mentioned, the form of slang rarely differs from that of standard English, so figurative meaning is crucial. Literature scholars might take this to be surprising, but slang borders on poetry. Lighter (in Algeo, 2001: 225-226) neatly compares the two: very much like poetry, slang is highly connotative and defamiliarizes the mundane world, and it implies that ordinary language is not quite adequate for certain tasks. Interestingly, African American slang employs many of the same figurative devices found in poetic language: metaphor, metonymy, synecdoche, allusion, hyperbole, meiosis, simile and personification. Let us discuss them in detail.

\section{Metaphor}

Metaphor is the most well-known figure of speech associated with figuration. In a broader sense, it can be understood as the application of a word or phrase to someone or something where it is not meant literally, but is rather used to make a comparison. More specifically, metaphor crosses certain conceptual boundaries, often called domains, and names something by a different name. In this way, it brings likeness or analogy between things that are fundamentally dissimilar. For instance, a snake can mean 'a secretive, treacherous or dishonest person' because the behavior of such people is similar to what is commonly thought to be the behavior of snakes; the domains, however, are entirely different. In common consciousness, metaphor belongs to poetry, where for centuries it has been admired for its ability to cross the boundaries of human thought and experience.

Metaphor is by no means exclusive to poetry and is used extensively in African American slang as well. This is because of slang's tendency to avoid naming things directly on the one hand, and to evoke striking connotations on the other. Here is a modest selection of slang metaphors:

'Say, daddy-o, what ax [= musical instrument] do you play?' 'Piano' - Ray, film, 2004

That woman is a real brick [= sexually attractive woman, especially if curvaceous] - Birmingham Post, 2001 
He's an ordinary cat [= rap or hip hop musician] from outta projects - WuTang Clan, 1998

George has enough cheese [= money] to pay ten men that type of salary Bradenton Herald

He was diesel [= muscular and handsome man] 'til he started smokin' crackRandy Kearse, 2006

Somebody told my dog [= friend] we were ranked 30th in the league - Sacramento Bee, 1998

He sells his dust [= any drug in powder form, especially PCP] up on the Lower East - Wu-Tang Clan, 1997

Bitch, don't ask me why I gotta a nice grill [= face]. This is just how my face is - Remy Ma, 2006

That Bobbitt dame took a sling blade to her husband's love muscle [= penis], did she not? - News, CNN-TV program, 2007

Trista used her delicate fingers to comb them out of her long moss [= hair] Fan Fiction, 2009

Allusion can be viewed as a form of metaphor. Many metaphors intensify their meaning by cultural allusions or via reference to an historical or literary event, person or place; quite often, allusion is based on popular culture and leisure activities such as sports, movies, television and popular music. They may be fully comprehensible or appreciated only if one has the specific knowledge to which they refer. Representative examples include such expressions as: Alphabet City, Beam me up Scotty, City of Brotherly Love, get to second base, pull a MacGyver, king of soul, take the Pepsi challenge, Teflon Don or Volunteer State.

Such use is especially important in African American slang. This is because slang often relies on shared knowledge that can serve as a sign of belonging to a limited circle of people, exluding outsiders who do not possess specific knowledge. In fact, allusion is sometimes so specific that it makes slang incomprehensible for those not familiar with African American culture and history. Such use is consistent with the characteristic of slang as an arcane and secret language. The following citational findings reflect this:

While it is no longer Chocolate City [= city with a predominantly African American population] statistically, its spirit protects you - Ebony, 2009

It's going to cost a lot more dead presidents [= US dollar bills] this time around-Denver Post, 1998

African American men call it driving while black [= instance of stopping African American motorists for no apparent reason] — Fay Observer, 2010 
Where's our forty acres and a mule [= symbolic reparations for enslavement]? - Tupac Shakur, 2000

Monfriez took the pistol back and demonstrated an exaggerated gangsta grip [= holding an object, especially a gun, sideways] — Patrick Duncan, 1996

Michael has lived in Hotlanta [= Atlanta, Georgia] since graduating from Georgia Tech - Englewood Herald-Tribune, 1999

This is the Motor City [= Detroit, Michigan], and this is what we do Associated Press, 2011

She is a used Oreo cookie [= African American who has assumed the behavior and values of the dominant white society]. The white community used her and spit her out - Ebony, 2008

It's incessant rant about how much better everything is in the Rotten Apple [= New York City] - Sarasota Herald Tribune, 1999

I thought it was a slam dunk [= something or someone certain to win, especially with ease]. I really thought I had the job - News, KGBT-TV program, 2011

Some of the above examples may require explanation. For instance, forty acres and a mule originated during the Civil War and comes from 'Union General William T. Sherman's order for each ex-enslaved family to receive forty acres of land in coastal South Carolina and Georgia, and for the army to loan them mules' (Smitherman 2000: 135-136). The allusion in oreo cookie is a little more understandable since it comes from a popular brand of sandwich cookies, still its full understanding requires certain cultural knowledge stemming from African American experience; Smitherman (2000: 221) defines it as 'An African American who is Black in skin color but white in thinking and attitudes; like the cookie, black on the outside, white on the inside.' These and many more similar terms are usually incomprehensible for those unfamiliar with African American experience.

\section{Metonymy}

Metonymy is another productive figuration device employed in standard English. In metonymy, an attribute of something is used to stand for the thing itself. In contrast to metaphor, which crosses different domains, metonymy operates within a single domain and thus, as observed by Lakoff and Johnson (1980: 35), 'allows us to center more specifically on certain aspects of what is being referred to.' Examples of this productive figuration device include brass ('military officers') or the stage ('theatrical profession'). In synecdoche, 
considered a kind of metonymy, the part stands for the whole or vice versa, for instance, sail ('boat') or hand ('helper').

African American slang also makes heavy use of this figuration device. As in metaphors, most slang metonyms operate on the same principles as in standard language: the meaning of one word must be associated in some way with the meaning of another. There is a profusion of words in African American slang which have acquired new meanings in this way. Consider the following selection:

You got some booty [= woman considered as a sex object] in this house? ATL, film, 2006

He gonna tell me to turn down my box [= large portable stereo player] - Do the Right Thing, film, 1989

He actually looked forward to getting back to his den [= apartment or house] for some quality television time - St. Louis Post-Dispatch, 2005

The most asked question is how I got them digits [= telephone number]? - JayZ, 2000

Never thought I'd see a knight, Sir Ben Kingsley, smoking herb [= marijuana] with a member of the Wu-Tang Clan - Orlando Sentinel, 2008

Ladies and gentlemen, make some noise [= music, especially instrumental]! Hair Show, film, 2004

I penciled a note stating that he had owed me paper [= money] — Orlando Sentinel, 1997

My ride [= automobile] can't be that much of a hoopty, if it caught your attention - Timothy Carson, 2010

I'm gonna bring my steel [ = firearm] and pump bullets in your ass - Clockers, film, 1995

Get your white ass [= self, referring to a white person] away from that window! - Forrest Gump, film, 1994

\section{Other processes}

Hyperbole is another important device used in figuration. It refers to exaggeration or overstatement, usually deliberate and not meant to be taken literally. In the English language, everyday idioms are often hyperbolic, for instance flood of tears, tons of money or waiting for ages. Hyperbole is normally used for effect and emphasis, however, frequency of use lessens its impact. Moreover, hyperbole as a means of expressing exaggeration is especially typical of male talk, as observed by Flexner (in Chapman 1986: xxv). It is productive in African American slang possibly because of the sarcastic 
humor typically associated with it. Citational corroboration yields the following:

We put our minds together, made the tracks clever. Now we're checking more bank [= money] than ever -Ice-T, 1991

Ebony had an opportunity to talk to him about his background, how he got into classical music and how hard work pays big dividends [= money] $-E b$ ony, 2009

He was a jealous nigga and she was a hoe [= sexually promiscuous woman] Antione Cunningham, 2010

Dude, we gotta jet [= depart or leave], or we'll miss the concert! - Urban Dictionary, 2012

Before we kick the ballistics [= talk], first a few ground rules — Los Angeles Sentinel, 1996

Then Miss Thing tried to scream on [= criticize and disrespect] my brethrenDr. Dre, 1999

They've gotta know we're as serious as a heart attack [= very serious] Youngstown Vindicator, 2011

He couldn't get a slave [= job]; he apparently drank all the travel money up Scott Newhall, 1990

On top of gossip, guests got to hear some great live music from Soul City [= Harlem, New York] - Boston Herald, 1998

If you like her, wife [= make her your steady girlfriend] her and if you love her, smother her - Snoop Dogg, 2008

The opposite of hyperbole is meiosis (alternatively termed litotes), another frequently used figuration device. It is an ironic understatement that dismisses or belittles, specifically by using expressions that make something less significant than it really is or should be, for instance calling a serious wound a scratch, or calling a stupid person not exactly intelligent. It is also used is African American slang, again likely for its sarcastic humor. Here is some citational corroboration from our database:

I got biyatches. I got plenty of chedda, and a phat crib [= apartment or house] - Janet Perr, 2008

An armored car full of dead presidents [= US dollar bills] is on its way to the incinerator - Washington Post, 2000

The seventy-three-year-old Odessa Madre revealed part of her painful past that led her to despise the e-lites [= elite] - Sharon Harley, 2002

Bookhart grew up wanting to fly the ghetto bird [= police helicopter, often used in inner-city ghetto cummunities] — Pitch Weekly, 2006

When you go downtown, y'all wear your ghetto rags [= clothes typical of the 
inner-city ghetto]. Don't go down there with your Italian silk jerseys Tom Wolfe, 1980

'I got some paper [= money] for you!' 'Now we're talking!' - Coach Carter, film, 2005

A black man would never dream of talkin' to the PO-lice [= police] high Chapelle's Show, WGN-TV program, 2010

He just wasted [= killed] him, blew him away! And I went right along with itCode of Silence, film, 1985

It seems to be able to take more torque then manuals. Sounds like a cool trans [= automobile]. Any pics? - Lateral G, 2010

Simile is yet another figure of speech used in figuration. It involves a more-or-less fanciful or unrealistic comparison between one thing and another, typically using the words like or as. There are numerous expressions in English based on simile, for instance, (as) cool as a cucumber, (as) red as a beet or (as) white as a sheet. Simile is also employed in African American slang where it is normally used to strengthen or emphasize a given quality. Here are representative slang examples:

It's brilliant stuff, and funky as a motherfucker [= extremely or totally] - Music Vice, 2010

She was as barefoot as a river duck [= barefoot], my mama would say, complaining that her feet hurt, and she had started her period - Darnail, 2003

We're going to get drunk like motherfucker [= extremely or totally] — Google News Archive, 2009

We were on her like white on rice [= clinging to or following as closely as possible] to be sure her promises were not hollow - Belief Net, 2010

I immediately detected the smell of marijuana wafting from the vehicle. He was lit up like a Christmas tree [= under the influence of a drug] - Sure Fire, 2010

Let me start off by saying that this is strictly a rumor, so don't take this as serious as a heart attack [= very serious] or anything like that - Bleacher Report, 2011

Finally, there is personification, which is often regarded as an aspect of metaphor. It refers to the attribution of human qualities to objects or abstract notions, as in Mother Nature, Old Father Time, one-armed bandit, or Uncle Sam. African American slang employs personification, too, with much the same effect as standard English. Here is a handful of citational examples of personification found in our database:

They'll keep coming back to drop a few more wads of Benjamins [= hundred 
dollar bills] for the benefit of our community - Alamogordo Daily News, 2010

To all y'all talkin' about dude bein' a junkie; he snorted girl, not boy [= heroin]! - World Star Hip Hop, 2010

She had a split at both sides of her dress and her breasts were big mamas [= big things] - Rick Van Dam, 2006

But without Franklin faces [= hundred dollar bills] you see who's your real friends - Rap Genius, 2011

I had watched him snort girl [= cocaine] and down a few mixed drinksRobert Beck, 2004

A mixed signal is when you're saying 'no' but you got your hand on my Jim Browski [= penis] - Access Atlanta, 2009

We got one guy wearing Jordans [= gym shoes] all the time - Daily of the University of Washington, 2011

This thing is a mother [= something big or troublesome] to take apart by yourself-Macleans, 2009

We're building a house, the second story's looking good. We've got to put the roof on this motherfucker [= something big or troublesome] — Artist Direct, 2010

\section{Shifting}

Semantic shifting is an established mechanism of change in the meaning of words. It involves such semantic processes as generalization, specialization, melioration and pejoration, all of which can affect both denotative and connotative meaning. Shifting is usually associated with the passage of time: in standard language, it is visible in historical shifts into new meanings, which are perceived as a series of increasing divergences from the older, established meanings. For instance, the word gay once meant 'merry' but shifted denotation to mean 'homosexual'.

Since much of slang is formed from old words which acquire new meanings, semantic shifting is strongly featured in African American slang. By way of analogy, the meaning of a slang expression can be described as a series of increasing divergences from standard meanings in a manner similar to changes in language throughout history. There are numerous expressions which changed their meanings in this way; for instance, the expression Ann was first used to mean 'a white woman' but, through shifting, came to be used for 'an arrogant African American woman who acts like a white person'. All these shifting processes are employed in African American slang.

Generalization (alternatively termed broadening or extension) widens the 
denotative meaning of a word, rendering it broader or more inclusive over time. In English, many words have acquired their current meaning through this process. For instance, novice once meant 'an initiate in a religious order' but has widened its meaning and now can be used to refer to 'any beginner in any field or discipline'.

African American slang expressions show generalization as well. The meaning is widened with regard to standard words that become slang in this way, but also with regard to words that are already slang and have acquired additional meanings. Here is a selection of expressions whose meaning became generalized:

He's got a bigass [= generally big, not just having big buttocks] peacock right here - Heat, film, 1995

It's hard for him to chill out [= have a good time, not just be calm] - Showbiz Spy, 2010

Alexander looked cokey [= generally inattentive or sleepy-looking, not just under the influence of cocaine] tonight - Boxing Scene, 2010

With my nigs, dividends [= money in general, not just profit paid to stockholders] flow - Jay-Z, 2006

Your funds [= money in general, not just amount of money saved or invested] are tight - Hair Show, film, 2004

If a woman was promiscuous, she was a ho' [= any sexually promiscuous woman, not just a prostitute], no explanation needed - Mary Morrison, 2009

She is totally my homey [= any close friend, not just a member of a criminal gang or a fellow African American person] — Los Angeles Times, 2010

Cookbook author Marlena Spieler has a jones [= any intense craving or desire, not just a drug habit] for cheese - Kansas City Star, 2006

Every hot mama [= any woman, especially older, not just someone's mother] here was checking him out - 3rd Rock from the Sun, NBC-TV series, 1999

Bullets can't kill a ninja [= any tough person, not just a Japanese martial arts expert]! - Urban Dictionary, 2010

Specialization (or narrowing) is the opposite of generalization. It involves semantic change in which the denotative meaning of a word becomes narrowed, less general or less inclusive over time. Again, many English words have arrived at their current meanings through this process. For instance, meat once simply meant 'food' but has narrowed its meaning and now is used only to refer to 'the flesh of an animal used as food'.

Many African American slang expressions can also be explained as instances of specialization. Again, the meaning is narrowed with regard to standard words that become slang in this way, but also with regard to words that 
are already slang. Here is a selection of items whose meaning have become specialized:

He had an attitude [= arrogant, condescending or uncooperative attitude, not any attitude], he was rude - Public Enemy, 1992

It's always five dollars a bag [= quantity of prepackaged drugs sold on the retail level, not just any bag] - Transamerica, film, 2009

Grab the box [= large portable stereo player, not just any box] and wait Arrested Development, 1992

I need to get your digits [= telephone number, not any set of digits] - ATL, film, 2006

Did you drill [= have sex with, not penetrate a surface making a hole] her friend yet? - Randy Kearse, 2006

A lot of other motherfuckers snort dust [= drug in powder form, not any fine, powder-like substance] - Burbler, 2010

They still bring the noise [= music, especially instrumental music rather than vocals, not just any noise] - Ebony, 2009

I just want to be the one to serve [= provide sexual favors to someone, not just serve in general] you - Geneva Smitherman, 2000

I know killers in the street with the steel [= firearm, not just any object made from steel] - Snoop Dogg, 2004

Waste [= to kill, not just to use carelessly or extravagantly] her! - Sister Act, film, 1992

Melioration (alternatively termed amelioration or elevation) is yet another semantic process of change in language. It involves an improvement in the meaning of a word whose connotations become more favorable over time. Historically, it accounts for many new meanings of English words; for instance, knight once meant 'a boy' or 'male servant' but has improved its meaning to refer to 'a noble soldier of higher rank' or 'a man who holds the title 'Sir',

Melioration is widespread in African American slang. This is probably because much slang is negative and involves taboo references to sexual acts, body parts and bodily functions. However, through increased use, these expressions lose their shock value and become more positive. For instance, the world of African American music was responsible for popularizing the meliorated meanings of jam, jazz, and juke, all of which originally had sexual references. Here are more examples of African American slang with ameliorated meanings:

It's a unique glimpse at the talented people who make Dallas a badass [= excellent or admirable] place to live - Pegasus News, 2008 
I'd love to shoot the shit with you bitches [= women] all night, but I gotta go Coach Carter, film, 2005

You burn [= cook, especially if very well] supper? Who's the lucky girl? Jungle Fever, film, 1991

Before you go, don't forget to give us that cheese [= money]. Why? Because we broke - Bamboozled, film, 2000

I honestly think that you're a cold [= excellent or admirable], dude! - Blu Light, 2010

The concert was hype, Boss delivered [= performed in an excellent or admirable way] - Geneva Smitherman, 2000

I love hanging out with my ho's [= women] and I love meeting new people My Yearbook, 2009

Back to the fact I'm the mack [= sexually active man who has many sexual partners] - Us3, 1993

I vouch for this motherfucker [= excellent or admirable man], he's a motherfucking genius - 8 Mile, film, 2002

Curtis can still write a motherfuckin [= excellent or admirable] song Google News Archive, 2009

Pejoration (alternatively termed degradation or degeneration) is the opposite of melioration. It involves a depreciation in the meaning of a word whose connotations have become less favorable or have worsened over time. Historically, pejoration has shaped the meanings of many standard words. For instance, silly once meant 'blessed' or 'innocent' but has worsened semantically to mean 'ridiculous' or 'trivial'.

This process is also encountered in African American slang, which generally favors mockery and degradation. Because of the generally negative tone of slang, pejoration is considered less evident than melioration (Eble 1996: 59). Our findings show that both processes operate with a similar degree of intensity. Here is a selection of African American slang expressions that have undergone pejoration:

I could never be a maid because I'd have an attitude [= arrogant, condescending or uncooperative attitude] - Seinfeld, NBC-TV series, 1991

No one was calling her a big, ugly bear [= unattractive woman] - Deseret News, 2007

You're not goin' anywhere, boot [= African American person]. You're goin' to jail-News, CNN-TV program, 1992

They ran a game [= deception or manipulation] on me, these two - Clockers, film, 1995

Why are dudes so geographical [= harboring prejudice against someone 
because of their place of origin] when it comes to music? - Realest Niggas, 2010

That bitch is a marshmallow [= white person, especially fat] - Urban Dictionary, 2009

So did they come to a decision on how to deal with him making Youkilis as his maytag [= flunky]? - Google News Archive, 2009

I was a kid living in the projects [= housing projects for the poor] - 30 Rock, NBC-TV series, 2009

He's a fuckin' snake [= treacherous person], you niggaz are fuckin' blind to facts! - Jay-Z, 2009

I don't matter if I marry Suzie, the fuckin' snowflake [= white person] - All Hip Hop, 2009

Sometimes, the melioration or pejoration in slang can be extreme and involve a total reversal of meaning. Antiphrasis, as it is technically called, is the use of an expression to mean the opposite of its usual sense, for instance saying that's wonderful when one really thinks something is terrible. Brasch calls this semantic inversion and considers it an important feature of African American lexis (1981: 295). Indeed, there are numerous examples of this interesting process in African American slang, possibly given a fondness for wordplay and semantic experimentation. Let us examine the following citational examples:

We got the bad [= excellent or admirable] bitches gaspin for air in Aspen Jay-Z, 1996

We are still blessed to have the baddest [= best] rock band in the world as ours - Ebony, 2009

If you know of an ill [= excellent or admirable] party or club event coming up, simply mail us and we'll post it here - McGill Party, 2009

The beat is so illin' [ = excellent or admirable] and real crazy all the way thru - TV Clip, 2010

That Cadillas Escalade is one bad-ass ride. I love the rims, they make that shit look mean [= excellent or admirable] - Aaron Peckham, 2005

Check out the brainy Brett! You're a smart motherfucker [= excellent or admirable man]! - Pulp Fiction, film, 1994

We'd have to be talking about one charming motherfucking [= excellent or admirable] pig - Pulp Fiction, film, 1994

Listen, the new Bugatti is one sick [= excellent or admirable] car! - Team Ninja, 2009

She was so vicious [= excellent or admirable], lips so luscious, suck a nigga dick and have it shinin like some dishes - Snoop Dogg, 2006 


\section{Summary}

Semantic change is a natural and well-established vehicle for language development. Its is also an important part of African American slang which is often created by attaching new meanings to previously existing standard English words, a process known as figuration, and changing previously existing meanings of these words, known as semantic shifting. In this aspect, African American slang is not different in any way from the standard English lexicon, where figuration and shifting are used extensively to form new meanings. This disproves any uninformed claims of the alleged linguistic deficiency of African American slang. Moreover, these two processes often feature in poetry, and their pervasive use in African American slang attests to great linguistic creativity and experimentation. Figuration in African American slang is extensive and involves metaphor, metonymy and several other processes; notable is the use of allusion peculiar to African American culture and the African American experience. Semantic shifting is extensive as well, and involves all four processes: generalization, specialization, melioration and pejoration. All of them occur in standard English and are connected with historical change in language. In African American slang, however, they happen more quickly and perhaps are therefore more conspicuous.

\section{REFERENCES}

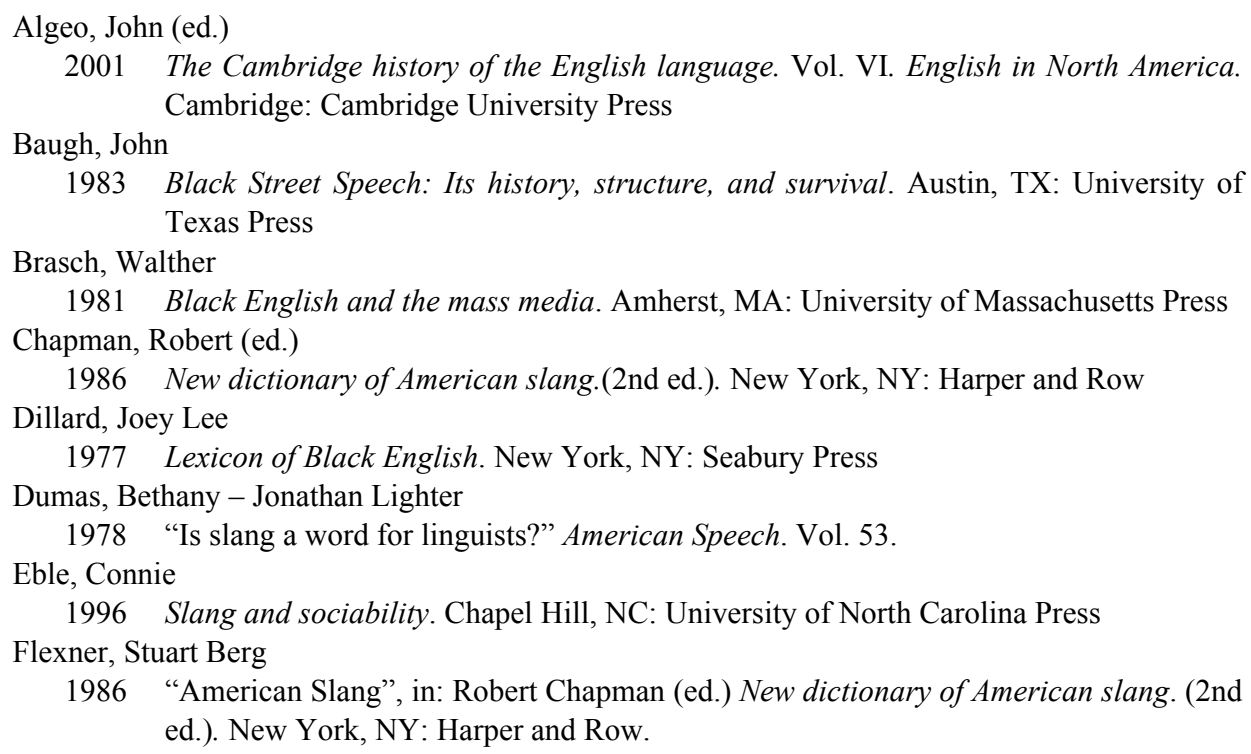


Folb, Edith

1980 Runnin' down some lines: The language and culture of black teenagers. Cambridge, MA: Harvard University Press

Kipfer, Barbara (ed.)

2007 Dictionary of American slang (4th ed.). New York, NY: HarperCollins

Lakoff George - Mark Johnson

1980 Metaphors we live by. Chicago, IL: University of Chicago Press

Lighter, Jonathan

2001 "Slang." In John Algeo (ed.) The Cambridge history of the English language. Vol. VI. Cambridge: Cambridge University Press. 219-252.

Major, Clarence

1994 From Juba to jive: A dictionary of African American slang. New York, NY: Penguin Books

Mesthrie, Rajend

2001 Concise encyclopedia of sociolinguistics. Kidlington, Oxford: Elsevier Science

Rickford, John

1999 African American Vernacular English: Features, evolution, educational implications. New York, NY: Blackwell

Smitherman, Geneva

1977 Talkin and testifyin: The language of Black America. Detroit, MI: Wayne State University Press

Smitherman, Geneva

2000 Black talk: Words and phrases from the Hood to the Amen Corner. Boston, MA: Houghton Mifflin

Thorne, Tony (ed.)

1990 Bloomsbury dictionary of slang. London: Bloomsbury Publishing

Widawski, Maciej

(forthcoming) African American: A linguistic description.

Widawski, Maciej - Małgorzata Kowalczyk

2012 Black Lexicon. Gdańsk: University of Gdańsk Press. 